\title{
Child Abuse and Neglect: Screening for Risks During the Perinatal Period
}

\section{Kindesmisshandlung und Vernachlässigung: Risiko-Screening in der Geburtshilfe}

Authors

Affiliations
T. Besier ${ }^{1}$, M. Pillhofer ${ }^{1}$, S. Botzenhart ${ }^{1}$, U. Ziegenhain ${ }^{1}$, H. Kindler ${ }^{2}$, G. Spangler ${ }^{3}$, I. Bovenschen ${ }^{3}$, S. Gabler ${ }^{3}$, A. K. Künster ${ }^{1}$

${ }^{1}$ University Department of Child and Adolescent Psychiatry/Psychotherapy, Ulm

${ }^{2}$ German Youth Institute (DJI), Munich

${ }^{3}$ University of Erlangen, Department of Developmental Psychology and Educational Psychology, Erlangen
Key words

early prevention and intervention

- obstetrics

- child protection

- prevention

- screening

\section{Schlüsselwörter}

- Frühe Hilfen

- Geburtshilfe

- Kinderschutz

- Prävention

- Screening

\section{received 8.12.2011 \\ revised 12.2.2012 \\ accepted 6.3.2012}

Bibliography

DOI http://dx.doi.org/

10.1055/s-0031-1298442

Geburtsh Frauenheilk 2012; 72 :

397-402 @ Georg Thieme

Verlag KG Stuttgart · New York · ISSN 0016-5751

\section{Correspondence}

Dr. Tanja Besier

University Department

of Child and Adolescent

Psychiatry/Psychotherapy

Steinhövelstraße 5

89075 Ulm

tanja.besier@uniklinik-ulm.de

\section{Abstract}

$\nabla$

Purpose: Currently, there is a claim for earlier interventions for families in order to prevent child maltreatment. Here, a screening instrument to assess risk indicators for child abuse and neglect already in the context of maternity clinics is introduced. The present study is the first report on the psychometric properties of this instrument, the "short questionnaire for risk indices around birth" (RIAB).

Material and Methods: Data were collected in the context of three different studies conducted at Ulm University Hospital. To examine interrater reliability eight case vignettes were rated by $\mathrm{n}=90$ study participants (50 students and 40 experts working at a maternity clinic). Criterion validity was examined in two studies applying the German version of the child abuse potential inventory CAPI ( $n=96$ families at risk and $n=160$ additional families).

Results: Both laymen and experts were able to understand and use the screening instrument correctly, leading to a high agreement with the sample solutions given. A high concordance was found between parents' and experts' ratings: In case of no reported risk factors applying the screening instrument RIAB, parents themselves reported significantly less stressors and burdens, compared to those parents with an indication for a thorough examination as pointed out in the RIAB.

Conclusion: In the context of maternity clinics the RIAB is a useful, broadly applicable instrument, screening for existing risk factors at the earliest and thus allowing for the initiation of specific interventions when needed.

\section{Zusammenfassung \\ $\nabla$}

Fragestellung: In der derzeitigen Kinderschutzdiskussion wird ein immer früherer Beginn von Hilfen für Familien gefordert. Vorgestellt wird ein Screening-Fragebogen zur Erfassung von Risikoindikatoren für Misshandlung und Vernachlässigung bereits in der Geburtshilfe, der „Anhaltsbogen für ein vertiefendes Gespräch“. Erste Untersuchungen seiner Testgütekriterien werden dargestellt.

Material und Methodik: In die Analysen gingen Daten aus 3 Studien der Universitätsklinik Ulm ein. Zur Untersuchung der Interraterreliabilität wurden 8 Fallvignetten von 90 Personen (50 Studenten und 40 Experten aus der Geburtshilfe) beurteilt. Auf der Basis von 2 Studien wurde außerdem die Kriteriumsvalidität unter Verwendung des Eltern-Belastungs-Screenings (EBSK; $\mathrm{n}=96$ Risikofamilien +160 weitere Familien) untersucht.

Ergebnisse: Reliabilität: Der Anhaltsbogen wurden von Laien und Fachkräften gleichermaßen gut verstanden und im Einklang mit einer Musterlösung korrekt verwendet. Validität: Fremdund Selbsturteil wiesen eine beachtliche Übereinstimmung auf: Wurden im Anhaltsbogen von den Fachkräften keine Risikofaktoren angegeben, berichteten die befragten Eltern selbst von einer signifikant geringeren Belastung, als dies bei den Eltern mit Anhaltspunkten für ein vertiefendes Gespräch der Fall war.

Schlussfolgerung: Der Anhaltsbogen ist ein praktikables, breit einsetzbares Instrument zum Einsatz in der Geburtshilfe, um bestehende Belastungen zu einem frühen Zeitpunkt zu erkennen und zum Wohle des Kindes bedarfsgerechte Unterstützung einzuleiten. 


\section{Introduction and Definition of the Problem} $\nabla$

In view of the potential for harm of early neglect and abuse as well as the difficulty associated with identifying cases reliably, more work has been carried out in Germany over recent years on expanding "early prevention and intervention" services. Early prevention and intervention services are entirely voluntary primary and secondary preventative local support systems offering facilities for families from the start of pregnancy with a focus on the first three years of life (cf. definition by the Scientific Council of the National Centre for Early Prevention and Intervention, http://www.fruehehilfen.de/wissen/fruehe-hilfen-grundlagen/ begriffsbestimmung/). These systems have demonstrated themselves at least on an international level to reduce the prevalence of early neglect and abuse by around one third [1].

Although child protection is not a key area of focus for gynaecology and obstetrics, maternity clinics are increasingly encroaching onto the radar of child protection efforts in Germany (cf. [2]). This has arisen from the fact that even stressed families appear to be particularly amenable to offers of support around the time of the birth [3]. Since over 98\% of babies are born in hospital in Germany (Federal Statistics Office, www.destatis.de), maternity clinics provide the ideal environment for documenting almost the entire population of newborns with minimal effort.

According to several broad-based longitudinal studies, (inter-)national literature documents well confirmed risk factors for child development [4-7] and dangers to children's wellbeing [8,9]. In the stages of early childhood in particular, there have so far been very few, if any, practicable and empirically confirmed procedures for detecting and documenting risks [10]. Unlike situational interventions in acutely at-risk situations, early assessment of risks appears to be central for averting the potential endangerment of children or at least making it less likely through targeted preventative services and interventions.

The short questionnaire for risk indices around birth (RIAB) [9] has been developed as a risk screening questionnaire and is already being used in several maternity hospitals in Germany. Until now, there has been no analysis of the psychometric properties of this instrument. This study therefore intends to present the first results on the inter-rater reliability and validity of this questionnaire for use in the field of obstetrics. The study will also investigate whether the systematic use of this screening method can be implemented as a routine in maternity hospitals around the perinatal period.

\section{Materials and Methodology of the Studies} $\nabla$

\section{Instruments used}

Short questionnaire for risk indices around birth (RIAB)

The short questionnaire for risk indices around birth (RIAB) [9] was developed as part of the model project entitled "Guter Start ins Kinderleben"1 [11], based on the systematic research of liter-

\footnotetext{
1 The model project entitled "Guter Start ins Kinderleben" was developed and sponsored as part of a joint initiative by the Federal States of BadenWürttemberg, Bavaria, Rhineland Palatinate and Thuringia. The evaluation was sponsored by the German Ministry for Families, Pensioners, Women and Youth and the National Centre for Early Prevention and Intervention as part of the campaign programme "Early assistance for parents and children and social early warning systems" and the National Centre on Early Prevention (http://www.uniklinikum-ulm.de/kjpp).
}

ature on relevant risk factors for the endangerment of children's wellbeing and developmental characteristics. On this basis, and together with the obstetrics services at the St. Marien und St. Annastift Hospital in Ludwigshafen, the "short questionnaire for risk indices around birth (RIAB)" which is being reviewed here was developed. It queries five superordinate risk areas which cover the majority of the risk factors identified:

A. At least one particular social stress.

B. Several missed ante-natal/paediatric health screening appointments.

C. The child has marked care needs that threaten to exceed the family's capabilities.

D. Evidence of significant difficulties on the part of the primary caregiver with accepting and caring for the child.

E. Primary caregiver describes severe anxiety about the future, feeling overwhelmed or feeling that the child has rejected him or her.

There are specifically formulated example factors for areas A, C and $D$ which can be used to carry out a targeted assessment of the risk area.

All five risk areas must be answered with yes/no with regard to their presence by members of the maternity hospital staff (generally midwives). If at least one risk is perceived, a more detailed discussion with the family is recommended in order to further clarify any risks and any need for support.

\section{German version of the child abuse potential inventory (CAPI)}

The German version of CAPI (EBSK, [12]) is a questionnaire for documenting the degree of stress felt by parents (subjectively) as an indicator for the risk of their child's welfare being endangered. The procedure involves a primary clinical scale for documenting parental stress levels (S values). To compensate for missing values, a conservative $S$ value $\left(S_{\text {cons }}\right)$ and a critical $S$ value $\left(\mathrm{S}_{\text {crit }}\right)$ can be used. The raw values can be assigned in accordance with a traffic light scheme to a green $(S \leq 161)$, yellow $(161 \leq \mathrm{S} \leq 185)$, orange $(185 \leq \mathrm{S} \leq 207)$ or red $(207>\mathrm{S})$ area, which represent an escalating risk of the possible endangerment of a child's wellbeing. The internal consistency of the CAPI is classed as good at $\alpha=0.91$. In a validation study, the CAPI was able to distinguish between groups of abusive and non-abusive parents and currently represents the only self-reporting process suitable as a criterion for the validation of the RIAB.

\section{Study design}

To verify the RIAB's test quality criteria, data are used that has been obtained from three different studies by the Ulm University Hospital's Department of Child and Adolescent Psychiatry/Psychotherapy. All of the studies were carried out in accordance with the guidelines set down by the Ethics Committee of the University of Ulm.

\section{Study 1: Inter-rater reliability}

In order to verify the consistency of the assessors with the RIAB, eight case vignettes were created that differed in terms of the nature and severity of the risk factors. The case vignettes each comprised a short, descriptive text and a subsequent video sequence on mother/child interaction. These vignettes were shown to two groups of assessors; one group of students and one group of professionals. The student group comprised 50 students in their second semester of Human Medicine at the University of Ulm 
$(M=22.9$ years, $56 \%$ female), who were given the case vignettes and RIAB as part of a block psychology course in July 2010. The group of professionals comprised 40 employees from maternity hospitals (primarily midwives, nurses and doctors, $M=40.9$ years, $95 \%$ female) who had been recruited from a total of seven hospitals and who worked on the case vignettes between October and December $2010^{2}$. In order to assess the estimates of the case vignettes by the students and professionals, a sample solution was drawn up for each case. If a particular risk indicator was mentioned in the text that was explicitly listed in the RIAB's guidelines, the RIAB was answered with "Yes" in the relevant place. The videos were assessed using the CARE Index behavioural observation tool [13]. It groups the way parents interact with their child into the categories of sensitive, adequate, inappropriate and high risk. If an interaction was classified as inappropriate or at high risk, the item "Observable clear difficulties on the part of the main caregiver with accepting and caring for the child" on the RIAB was answered with "Yes".

\section{Study 2: Criterion validity (Guter Start ins Kinderleben)}

As part of the model project entitled "Guter Start ins Kinderleben" [11], mothers with particular conditions (mothers with psychiatric problems, young mothers, mothers with a migration background and mothers of children with special needs) were offered developmental psychology advice [14], which was accompanied scientifically from 2008 to 2011 as part of an evaluation study with a quasi-experimental design. The mothers involved were enrolled in the study within the first three months of their children's life and took part in a baseline survey as well as attended seven sessions of developmental psychology advice in the intervention group and attended several follow-up appointments within the first year of their children's life. At the first measuring point, not only was the RIAB used, but so too was the German version of the CAPI. The random sample analysed here comprises the data from the baseline survey (intervention and control group) before the developmental psychology counselling began. All in all, 96 mothers aged between 15 and $40(M=22.9$, $\mathrm{SD}=6.1$ ) were included in the random sample. A description of the random sample can be found in $\bullet$ Table 1.

\section{Study 3: Criterion validity}

(pilot study in Ortenau county) and feasibility

Data for the validation of the short questionnaire for risk indices around birth were also obtained from a pilot study in Ortenau county in the State of Baden-Württemberg ${ }^{3}$. The feasibility of using the RIAB as a routine screening tool in maternity hospitals was also examined. From October to December 2010, the questionnaire was used in all six maternity hospitals in the county. The hospital employees were given training on how to fill out the questionnaire correctly, what its goals were and where it would be used. In view of the high number of hospital births, it can be assumed that this sample is representative of this county. All in all, specialists at the maternity hospitals completed a RIAB for every admitted mother ( $n=828$ questionnaires). The ques-

\footnotetext{
2 The investigation of the inter-rater reliability of the RIAB was carried out as part of the dissertation project by medical student Simone Botzenhart (University of Ulm, Faculty of Medicine).

3 The project entitled "short questionnaire for risk indices around birth" in Ortenau county was sponsored by the National Centre for Early Prevention and Intervention (NZFH; www.fruehehilfen.de).
}

Table 1 Random sample description of Study 1.

\begin{tabular}{|c|c|c|}
\hline Total $(n=96)$ & Number & Percentage \\
\hline \multicolumn{3}{|l|}{ Nationality } \\
\hline - German & 81 & $85.3 \%$ \\
\hline - Turkish & 5 & $5.3 \%$ \\
\hline Other & 10 & $9.4 \%$ \\
\hline \multicolumn{3}{|l|}{ Socio-economic status } \\
\hline - Income $<€ 1000$ & 63 & $71.6 \%$ \\
\hline - Low education & 58 & $60.4 \%$ \\
\hline \multicolumn{3}{|l|}{ Marital status } \\
\hline Single & 69 & $72.6 \%$ \\
\hline - Married & 20 & $21.1 \%$ \\
\hline Divorced & 6 & $6.3 \%$ \\
\hline \multicolumn{3}{|l|}{ Sex of the child } \\
\hline - Male & 42 & $43.8 \%$ \\
\hline - Female & 54 & $56.3 \%$ \\
\hline \multicolumn{3}{|l|}{ Number of sibling children } \\
\hline$>0$ & 59 & $62.8 \%$ \\
\hline$>1$ & 20 & $21.3 \%$ \\
\hline$>2$ & 6 & $6.4 \%$ \\
\hline$>\geq 3$ & 9 & $9.6 \%$ \\
\hline Wanted child & 49 & $51.6 \%$ \\
\hline \multicolumn{3}{|l|}{ Week of confinement } \\
\hline$-\leq 37$ week of pregnancy & 25 & $27.2 \%$ \\
\hline \multicolumn{3}{|l|}{ Birth weight } \\
\hline$><1500 \mathrm{~g}$ & 6 & $6.4 \%$ \\
\hline$><2500 \mathrm{~g}$ & 10 & $11.6 \%$ \\
\hline Existing birth risks & 50 & $53.2 \%$ \\
\hline
\end{tabular}

tionnaires were completely anonymised and, for data protection reasons, contained absolutely no socio-demographic details about the mothers. A precise description of the original study and its results are available elsewhere [15]. Even once the study had been completed, the RIAB was used for every birth at one hospital in Ortenau county. This meant that a smaller add-on study linked to the first study could be carried out which provided data for this analysis of the RIAB's validity ${ }^{4}$. All of the mothers who gave birth between November 2010 and January 2011 in a hospital in Ortenau county were asked to fill out the German version of the CAPI. During the study period, 761 children were born in the six maternity hospitals; however, the number of multiple births is not clear, which means that it must be assumed that there were fewer mothers than newborn children. All in all, 160 mothers (around $21 \%$ ) consented to take part. Complete data records are available for all 160 mothers (RIAB and German version of the CAPI) and were used in the analyses shown here.

\section{Methods of Evaluation/Statistical Methods \\ $\nabla$}

The data entry and all statistical calculations were carried out using the programme suite SPSS for Windows (Version 18.0.0). To calculate inter-rater reliability, the percentage consistency of the ratings with the sample solution was calculated. To evaluate the

\footnotetext{
4 This additional study was carried out as part of the Masters thesis by Vanessa Roudil d'Ajoux (Ludwig Maximilians University Munich, Faculty of Education and Psychology) under the direction of the Department of Child and Adolescent Psychiatry/Psychotherapy, Ulm University Hospital.
} 
validity of the RIAB, the random samples from Study 2 and Study 3 were merged in order to produce a larger random sample with good coverage of the entire risk spectrum. Frequency statistical methods $\left(\mathrm{X}^{2}\right)$ were used.

\section{Results}

$\nabla$

\section{Feasibility}

In Study 3, the RIAB was introduced as the standard tool for documenting all births in all six maternity hospitals within one county. All mothers were screened with it during their perinatal stay and more detailed discussions were held if they required it. In the original study mentioned [15], the RIAB was filled out as part of normal everyday hospital practices in at least $94.8 \%$ of births (since twins or triplets are taken into account only once in the RIAB). The hospital staff members who filled out the RIAB as part of the pilot study were also positive about its usability in hospital routines (time required for completion, preparation).

\section{Descriptive results: Risk factors that become apparent from the RIAB}

In 94 mothers ( $\mathrm{n}=96$ ) of Study 2 (validity: Guter Start ins Kinderleben), the advisers specified at least one risk factor. In one case, the RIAB was not completed or no risk factor was identified. Psycho-social stresses formed the main focus of the problems faced by many mothers $(n=91 ; 95.8 \%)$. The second most common problem was increased care needs of the child ( $n=19 ; 20.0 \%)$. These were followed in equal numbers by observations of difficulties accepting and caring for the child as well as fears about the future, feeling overwhelmed or rejection of the child by the mother ( $n=16 ; 16.8 \%$ ). The least common problem was missed ante-natal or paediatric examinations ( $n=4 ; 4.2 \%$ ). In 38 out of 94 cases (39.6\%), several of the named indicators were identified (two to a maximum of four indicators).

In Study 3 (validity; pilot study in Ortenau county), the professionals in the maternity hospitals identified at least one risk factor in the overall random sample of $n=828$ in $20.3 \%$ of cases. The data from the annexed add-on study, in which the test subject recruitment was linked with the willingness to fill out a further questionnaire, demonstrated much lower figures. In 17 of the 160 cases recorded ( $10.6 \%$ of the random sample), the professionals specified at least one risk factor. The most common of these ( $n=15 ; 9.4 \%$ ) was psycho-social stress. A more rare concern was the child's increased care needs ( $n=3 ; 1.9 \%)$. The feeling of anxiety about the future or being overwhelmed, and a lack of antenatal checkups in pregnancy were rarely cited (in only one case, corresponding to $0.6 \%$ ). In 3 of the 160 cases (1.9\%), two of the risk factors specified were recorded.

\section{Results of the inter-rater reliability (Study 1)}

- Table 2 shows the proportion of answers that tallied with the sample solution, divided into student and the professional groups as well as amongst all test subjects. The size of the random sample varies from item to item, since not all students and professionals were able to work through all vignettes for time reasons.

It is apparent that a very high proportion of the answers in both groups tally correctly with the sample solution for all five items. On review of the five individual risk areas, it becomes clear that areas A-D were assessed comparatively well by the raters, with an average of 92.3-94.0\% correct identifications, whereas the assessment of area $\mathrm{E}$ (anxiety about the future) only tallied with the sample solution in $89.9 \%$ of cases on average.

\section{Results of validity (Studies 2 and 3 )}

For the analysis of validity, $\mathrm{n}=92$ cases from Study 2 were analysed for which both the RIAB and the German version of the CAPI were available. In a categorical allocation of the conservative $S$ values (green, yellow, orange, red), there were no significant differences in the distribution between the group with indicators for a more detailed discussion and the group without $\left(X^{2} 3.92=2.0\right.$; n.s.).

In $n=159$ cases in Study 3, for which both instruments were also available, there were also no significant differences in the distribution between the group with indicators for a more detailed discussion and the group without $\left(X^{2} 3.159=1.2 ; n\right.$. s. $)$.

Consequently, the cases from Study $2(n=92)$ and Study $3(n=$ 159), for which both the RIAB and the German version of the CAPI were available, were merged $(n=251)$. In this case, no risk factor was identified in 145 cases (57.3\%), whereas at least one indicator for a more detailed discussion was identified in 108 cases (42.9\%). In mothers without indicators for a more detailed discussion, the CAPI values were $\mathrm{S}_{\text {cons }}=159.0$ and $\mathrm{S}_{\text {crit }}=160.5$, significantly lower than in mothers with at least one indicator for a more detailed discussion $\left(\mathrm{S}_{\text {cons }}=168.7\right.$ or $\left.\mathrm{S}_{\text {crit }}=171.8\right)$. In a categorical allocation of the conservative $S$ values (green, yellow, orange, red) (cf. $\odot$ Table 3), there was again a significant difference in the distribution between the group with indicators for a more detailed discussion and the group without $\left(X^{2} 3.251=8.8 ; \mathrm{p}<0.01\right)$.

\section{Discussion/Conclusions \\ $\nabla$}

This paper presents for the first time data regarding the psychometric properties of an instrument developed in Germany for the very early screening of risk concerning the endangerment of children's wellbeing. The use of the "short questionnaire for risk indices around birth" (RIAB) in six different maternity hospitals shows that the early screening of risk factors for (potential) later

Table 2 Results on the inter-rater reliability of the RIAB (short questionnaire for risk indices around birth)*

\begin{tabular}{|llll} 
& \multicolumn{3}{l}{ Number of assessments that match the sample solution } \\
& Overall group & Students & Professionals \\
\hline Item 1: Social stresses & $93.75 \%(n=629)$ & $93.75 \%(n=375)$ & $93.75 \%(n=254)$ \\
\hline Item 2: Missed ante-natal/paediatric health screening appointments & $93.98 \%(n=634)$ & $94.62 \%(n=379)$ & $94.06 \%(n=255)$ \\
\hline Item 3: Increased care needs & $92.32 \%(n=620)$ & $93.75 \%(n=375)$ & $90.94 \%(n=245)$ \\
\hline Item 4: Obvious, significant difficulties & $93.96 \%(n=631)$ & $94.5 \%(n=378)$ & $93.75 \%(n=254)$ \\
\hline Item 5: Fear about the future, feeling overwhelmed & $89.86 \%(n=603)$ & $96.0 \%(n=384)$ & $82.0 \%(n=219)$
\end{tabular}

\footnotetext{
* (n) specifies how many assessments were available for each item. The number of assessments is derived from multiplying the cases with the number of people who worked on them.
} 
Table 3 Agreement of the RIAB (short questionnaire for risk indices around birth) (more detailed discussion no/yes) with the subjective assessments of the parents in the CAPI (child abuse potential inventory) (green/yellow/orange/red area).

\begin{tabular}{lccccc} 
& \multicolumn{2}{c}{ Conservative S value category } & & \multicolumn{2}{c}{ Total } \\
Green & Yellow & Orange & Red & \\
More detailed discussion & & & 16 & 4 & 143 \\
\hline - No & 82 & 41 & 17 & 11 & 108 \\
\hline Yes & 46 & 34 & 33 & 15 & 251
\end{tabular}

danger to children's wellbeing can be carried out systematically as part of everyday clinical routine. This is where the unique opportunity lies to reach virtually all families promptly, since over $98 \%$ of children are born in hospitals in Germany, and no other institution has this level of comprehensive access to young families. On this basis, families who appear to be systematically stressed can be offered preventative support.

The contents of this process were understood very well both by medical students who have relatively little practical experience and by specialists in obstetrics equally. The RIAB was used correctly, which is evident from an average agreement of almost 93\% between the estimates of the test persons for case vignettes and the sample solutions, which means it can be assumed that no specialist professional knowledge is needed to use the RIAB. The positive inter-rater reliability also indicates an adequate level of objectivity. The students were more accurate in their estimates for some of the items on the questionnaire than the group of professionals. One possible explanation for this is that the students, as novices, are more likely to focus on the sample factors formulated in the questionnaire and the explanations of the individual items/risk factors, whereas the professionals' estimates may possibly be influenced more by their prototypically organised case experience, which is a familiar phenomenon from expert research (e.g. [16]). For a subsequent verification step, it would be useful - on this basis - to compare the clinical forecasts of practitioners with the real predictive properties of the RIAB. The question also arises whether the case vignettes could be linked with sample solutions as an approach for E-training on the RIAB in order to increase reliability, particularly among practitioners.

The studies set out here provide the first indicators of the RIAB's criterion validity. Where the experts stated there were no risk factors in the RIAB, the surveyed parents themselves reported significantly less stress, as expected, than was the case among parents who had indicators inviting a more detailed discussion. These contexts were not found in the partial random samples from Study 2 and Study 3. In Study 2, the majority of mothers engaged in a more detailed discussion, whereas this was not the case for the mothers in Study 3. This fact is due to the methods used in the two studies. In Study 2, only mothers were included who had a known objective risk factor, whereas the test subjects in Study 3 were recruited on a voluntary basis, which led to a distortion of the random sample towards less stressed mothers (see also the discussion further down). In view of the low scatter in the RIAB, it was not possible to illustrate any relationships with subjective stress. However, the positive relationship in the merged random sample between the external and self-assessments recorded indicates the informative nature of the process, even taking into account the fact that self-reported stress cannot be a perfect external criterion since, in some cases, parents are not willing to acknowledge critical (internal) stresses [17] and in other cases of idealised self-perceptions make the external as- sessment even more valid than their own. This means that the RIAB can be classified as a valid instrument for external assessment, without the subjective assessments of parents losing any of their significance; subjective assessments should be documented using suitable tools.

As part of everyday clinical situations, the tool therefore appears highly practicable and has already proven its worth for a number of years in some hospitals, such as the St. Marien Hospital in Ludwigshafen, where an adapted version of the RIAB is used routinely under the name "LUPE questionnaire". The graduated procedure with the need for a more detailed discussion where stress factors are identified yields a significant boost in quality for hospitals and increases not only the team members' skills but also their own perceptions of their safety. The extra work for hospital personnel caused by using the tool, which can be integrated into existing anamnesis structures on the wards by specialists, occurs in the more detailed discussions that need to be carried out following the introduction of the process. However, it does not require a great amount of time to clarify specific needs and carry out targeted continuing measures, thereby significantly improving the families' care.

The studies used are subject to a few limitations which restrict the ability to generalise regarding the results shown here. In the add-on study on the use of the RIAB in maternity hospitals, 160 mothers were willing to complete the German version of the CAPI (EBSK). These mothers, who participated voluntarily in the add-on study for the pilot survey in Ortenau county, had significantly fewer risk factors and stresses (only in $10.6 \%$ of the random sample were indicators for a more detailed discussion identified, whereas this was the case in $20.3 \%$ of the anonymouslygathered pilot random sample), which means that it must be assumed that there is a selective distortion of the results towards less stressed families. In order to compensate for this, the data from the analyses of the validity were merged with the assessments by specialists from youth welfare and health care services in a study on at-risk mothers in various fields of activity, all of which exhibited at least one risk factor. The validity investigation merely tested the agreement of the external assessments in the RIAB with a method that documented the subjective stress of the mothers. In future studies, it would be better to check the predictive validity of the process by creating criteria that are as objective as possible - such as the longitudinal monitoring of peaks of behaviour that put child wellbeing at risk, as has been the case in a recent American study [18] - although a careful verification of ethical concerns must first be carried out for such studies. The degree of the questionnaire's sensitivity to change, which would be useful for the analysis of changes caused by assistance and support measures instigated as quality control, has so far not yet been verified. The integration of follow-up measurements to assess the stability of the results achieved would accordingly be ideal in the future. 
The strength of the study set out here lies in the use of the instrument by practitioners (Study 2 and 3). Consequently, the statements not only apply to use of the instrument under study conditions, but also provide information about the quality criteria of the method in everyday clinical situations. It was also possible to safeguard the practicability of the instrument through this study. Beyond the criterion validity, it was also possible to demonstrate that subjective and objective stress levels tally well in the context of the perinatal situation and its particular psychological and biological conditions. This also lends support for the use of the RIAB even in the maternity hospital or in the weeks following the birth.

\section{Conclusion \\ $\nabla$}

The short questionnaire for risk indices around birth (RIAB) represents the first practicable, broadly applicable tool for use in obstetrics that will allow comprehensive, very early risk screening and - if necessary - the systematic instigation of appropriate support measures for young families in order to promote their health and prevent dangers to children. These results provide the first indicators of the questionnaire's good inter-rater reliability and external validity. Consequently, mother/child pairs who were offered a more detailed discussion following the use of the RIAB as a risk screening method, and even according to their own subjective assessment, were significantly more stressed, i.e. exhibited a higher risk of behaviour capable of endangering the child and which could have a negative influence on the child's development.

\section{Conflict of Interest}

$\nabla$

The authors declare that they do not have any financial relationship with any company associated with the article.

\section{References}

1 Reynolds AJ, Mathieson LC, Topitzes JW. Do early childhood interventions prevent child maltreatment? A review of research. Child Maltreat 2009; 14: 182-206

2 Sann A, Rauschenbach T, Pott E. Frühe Hilfen für Eltern und Kinder ausbauen, verbessern, vernetzen - Das Aktionsprogramm „Frühe Hilfen für Eltern und Kinder und soziale Frühwarnsysteme“. Geburtsh Frauenheilk 2010; 70: 504-506
3 Künster AK, Ziesel B, Ziegenhain U. Je früher umso besser? Wann Kinderschutz beginnen sollte. Frühförderung Interdisziplinär 2009; 28: 51-60

4 Werner E, Smith R. Overcoming the Odds: High Risk Children from Birth to Adulthood. Ithaca: Cornell University Press; 1992

5 Werner E, Smith R. Journeys from childhood to midlife: risk, resilience, and recovery. Ithaca: Cornell University Press; 2001

6 Laucht M, Schmidt MH, Esser G. Motorische, kognitive und sozial-emotionale Entwicklung von 11jährigen mit frühkindlichen Risikobelastungen: späte Folgen. Z Kinder Jugendpsychiat 2002; 30: 5-19

7 Sroufe LA, Egeland B, Carlson E et al. The Development of the Person: the Minnesota Study of Risk and Adaptation from Birth to Adulthood. New York: Guilford; 2005

8 Stith SM, Liu T, Davies C et al. Risk factors in child maltreatment: A meta-analytic review of the literature. Aggression and Violent Behaviour 2009; 14: 13-29

9 Kindler H. Wie könnte ein Risikoinventar für Frühe Hilfen aussehen? In: Meysen T, Schönecker L, Kindler H, Hrsg. Rechtliche Rahmenbedingungen und Risikodiagnostik in der Kooperation von Gesundheitsund Jugendhilfe. Weinheim, München: Juventa; 2009

10 Kindler H, Ziesel B, König $C$ et al. Unterstützungsbogen für die Jugendhilfe: Bogen zur Unterstützung der Hilfeplanung im frühen Kindesalter. JAmt 2008; 10: 467-470

11 Ziegenhain U, Schöllhorn A, Künster AK et al. Modellprojekt Guter Start ins Kinderleben. Werkbuch Vernetzung. Chancen und Stolpersteine interdisziplinärer Kooperation und Vernetzung im Bereich Frühe Hilfen. Köln: Nationales Zentrum Frühe Hilfen; 2010

12 Deegener G, Spangler G, Körner W et al. EBSK. Eltern-Belastungs-Screening zur Kindeswohlgefährdung. Deutsche Version des Child Abuse Potential Inventory (CAPI) von Joel S. Milner. Göttingen: Hogrefe; 2009

13 Crittenden PM. CARE-Index Infants (birth-15 months). Coding manual. Unpublished manuscript. Miami, FL: Family Relations Institute; 2006

14 Ziegenhain $U$, Fries $M$, Bütow B et al. Entwicklungspsychologische Beratung für junge Eltern. Ein Handlungsmodell für die Jugendhilfe. Weinheim: Juventa; 2004

15 Ziegenhain U, Thurn L, Künster AK et al. Frühe Risiken für eine potentielle Kindeswohlgefährdung - eine Untersuchung in Geburtskliniken des Ortenaukreises. JAmt 2011; 8: 377-383

16 Berliner DC. The Nature of Expertise in Teaching. In: Oser FK, Dick A, Patry J, eds. Effective and responsible Teaching. San Francisco: JosseyBass; 1992: 227-248

17 Achenbach TM. Integrative Guide for the 1991 CBCL/4-18, YSR, and TRF Profiles. Burlington: University of Vermont, Department of Psychiatry; 1991

18 Brownell MD, Chartier M, Santos R et al. Evaluation of a newborn screen for predicting out-of-home placement. Child Maltreat 2011; 16 (4): 239-249

Deutschsprachige Zusatzinformationen online abrufbar unter: www.thieme-connect.de/ejournals/toc/gebfra. 